\title{
Interaction of Pindone and its Tautomers with Calcium Dication - A DFT Study
}

\section{Lemi Türker}

Department of Chemistry, Middle East Technical University, Üniversiteler, Eskişehir Yolu No: 1, 06800 Çankaya/Ankara, Turkey; e-mail: lturker@gmail.com; lturker@metu.edu.tr

\begin{abstract}
Calcium dication has an important role at various stages of blood coagulation mechanism. On the other hand, pindone is an important anticoagulant rodenticide which undergoes 1,3-type proton tautomerism to yield two enolic isomers of pindone. Although, the anticoagulant mode of action of pindone is attributed to blocking of a liver enzyme responsible for the recycling of vitamin $\mathrm{K}$, nothing is known about whether the interaction of it with calcium dication has some role as well. In the present study, the interactions of pindone and its tautomers with $\mathrm{Ca}^{++}$have been investigated within the restrictions of density functional theory at the level of B3LYP/6-311++G(d,p). It has been found that $\mathrm{Ca}^{++}$highly affects pindone and its tautomers in many respects at the molecular level, hence their anticoagulation effect should vary.
\end{abstract}

\section{Introduction}

2-Pivalyl-1,3-indandione, also known as pindone is an anticoagulant rodenticide of the indandione type, as are chlorophacinone and diphacinone [1]. It is reported that anticoagulant rodenticides inhibit the vitamin $\mathrm{K}$ dependent step in the synthesis of a number of blood coagulation factors [1,2]. The mode of action is attributed to blocking of a liver enzyme responsible for the recycling of vitamin $\mathrm{K}[1,2]$.

Received: November 11, 2019; Accepted: January 3, 2020

Keywords and phrases: pindone, 2-pivalyl-1,3-indandione, tautomerism, DFT, calcium.

Copyright (C) 2020 Lemi Türker. This is an open access article distributed under the Creative Commons Attribution License, which permits unrestricted use, distribution, and reproduction in any medium, provided the original work is properly cited. 


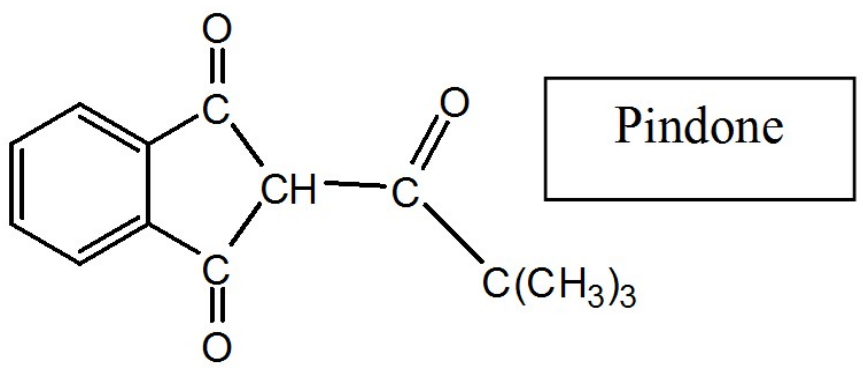

The first generation anticoagulant rodenticides such as pindone have largely been superseded by the syntheses and use of second generation anticoagulants of the hydroxycoumarin type, such as bromadiolone and brodifacoum. These compounds of novel type are lethal to target rodents after a single application, in spite of the fact that death is delayed for some days. It has to be noted that baits containing the indandiones and the first generation hydroxycoumarins are generally to be consumed repeatedly prior to death occurs.

Two chemical forms of pindone; pindone acid which is a mixture of keto and enol forms and pindone sodium (sodium salt of pindone), are used to prepare baits for rabbit control in Australia. The pindone acid has low water solubility while the sodium salt is soluble in water [1-5]. In terms of toxicity, the acid and salt forms of pindone can be equivalent once ingested because gastric acidity is usually strong enough to liberate the "free acid" from the salt. Thus, both forms of pindone break down to the same end product in the field application. Because of that they have the same non-target impacts to fauna.

A first generation anticoagulant pindone has been used to control rabbits in areas where the alternative poison, sodium fluoroacetate, is either impractical or unsuitable. Pindone inhibits the manufacture of blood clotting factors (prothrombin), leading to a reduction in the clotting ability of the blood. One of the advantages of pindone is the availability of an antidote in the case of accidental poisonings [6].

Both pindone acid and pindone sodium products are in use as a vertebrate poison to control rabbits in urban and semi-urban areas where sodium fluoroacetate cannot be used. Sodium fluoroacetate is usually preferred and used for rabbits because it is cheaper. However, the lack of an antidote for this substance makes it unsuitable for use in and around urban areas where domestic animals may be exposed. Pindone is the only reversible poison available for rabbit baiting in such situations [2-5]. 
Crystal structure of pindone was determined [7]. On the other hand, the tautomerism in indandiones has attracted attention especially in the past [8-11].

As implied by the name, all anticoagulants, including pindone, are toxic due to their ability to prevent blood clotting by inhibiting the formation/effectiveness of vitamin-K dependent clotting factors (e.g. prothrombin) in the liver. The liver is the main site of action where the blood clotting factors are produced. The toxic manifestations of anticoagulants are delayed for several days because time is required for the viable clotting factors circulating in the blood to become diminished, thus the effects of poisoning become apparent [12]. Increased prothrombin times (i.e. the time taken for the blood to clot) can be a useful indicator of the sensitivity of animals to these compounds as prothrombin times increase before the onset of hemorrhage $[3,13]$. Time to death with the anticoagulants ranges from 1-20 days. Most target animals will continue to feed well after they have ingested a lethal dose without any apparent ill-effects up until death occurs.

If administered within a certain time period, vitamin $\mathrm{K} 1$ is a powerful antidote to anticoagulant poisoning for the treatment of species accidentally poisoned (e.g. humans, domestic livestock) $[14,15]$.

The mechanism of blood clotting involves many reactions in mammalian plasma [1618]. Various proteins participate in the process. Evidence is that, if not all, most of them are enzymes which require $\mathrm{Ca}^{++}$or other divalent cations in several of the conversions $[16,17,19,20]$.

Pindone is an anticoagulant rodenticide and it may interfere blood coagulation process by some way. It might be via interaction with $\mathrm{Ca}^{++}$, thus reducing its active concentration necessary for many conversions in blood clotting process or by means of some other reactions.

In the present treatment, the interaction of pindone and its 1,3-type tautomers with $\mathrm{Ca}^{++}$has been investigated within the constraints of density functional theory (DFT).

\section{Method of Calculation}

Optimized geometries of pindone and its tautomers as well as their $\mathrm{Ca}^{++}$composites 
leading to energy minima have been achieved by using MM2 method prior to semiempirical PM3 self-consistent fields molecular orbital (SCF MO) method [21, 22] at the restricted level $[23,24]$. The subsequent optimizations of them have been achieved at Hartree-Fock level using various basis sets hierarchically. Finally, the structure optimizations have been managed within the framework of density functional theory [25, 26], finally at the level of B3LYP /6-311++G(d,p) [23]. The exchange term of B3LYP consists of hybrid Hartree-Fock and local spin density (LSD) exchange functions with Becke's gradient correlation to LSD exchange [26, 27]. Note that the correlation term of B3LYP consists of the Vosko, Wilk, Nusair (VWN3) local correlation functional [28] and Lee, Yang, Parr (LYP) correlation correction functional [29]. Also, the vibrational analyses have been done for all the structures. The total electronic energies have been corrected for the zero point vibrational energy (ZPE). The stationary points to energy minima were proved in all the cases by calculating the second derivatives of energy with respect to the atom coordinates. The normal mode analysis for each structure yielded no imaginary frequencies for the $3 N-6$ vibrational degrees of freedom, where $N$ is the number of atoms in the system. This indicates that each structure corresponds to at least a local minimum on the potential energy surface. All these calculations were done by using the Spartan 06 package program [30].

\section{Results and Discussion}

Coagulation mechanism is very complex $[17,18]$. Pindone and its tautomers in some way disturb occurrence of series of reactions in the coagulation mechanism. Up to the best knowledge of the author it is unknown yet at what stage of the coagulation mechanism pindone and its tautomers interfere. It is already known that $\mathrm{Ca}^{++}$has an important role in the coagulation process in mammals $[17,18,20]$. The anticoagulant effect of pindone and its tautomers could be due to its interaction with $\mathrm{Ca}^{++}$or by other mechanisms. Pindone has two 1,3-type proton tautomers (presently labeled as P1 and P2) which are also classified as keto-enol tautomers. Their tautomerisation interrelation has been shown below. 


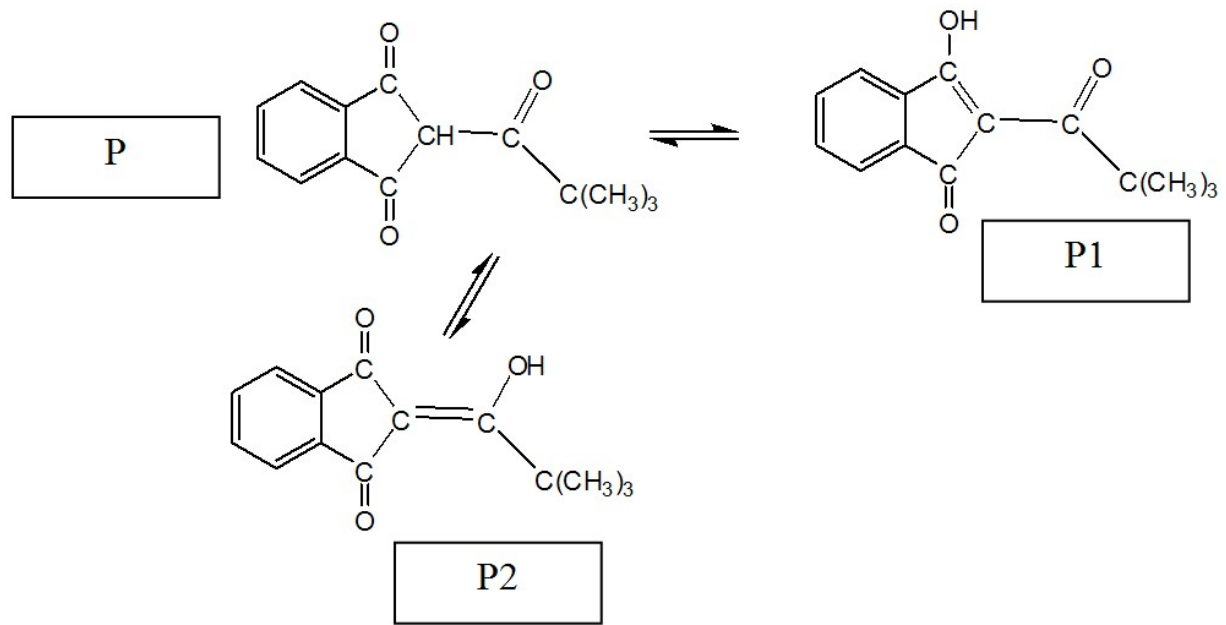

It has been recently investigated [31] that pindone, undergoes a 1,3-type keto-enol tautomerism to yield an endocyclic enol (P1) which is more stable electronically and more favorable thermodynamically than the isomeric 1,3-type exocyclic enol (P2) as well as pindone itself.

Figure 1 shows the optimized structures of $\mathrm{Ca}^{++}$composites of pindone, P1 and P2 $\left(\mathrm{P}^{*}, \mathrm{P} 1^{*}\right.$ and $\left.\mathrm{P} 2^{*}\right)$ as well as the direction of the dipole moment vectors. From now on the composite structures originated from pindone and its tautomers are symbolized as $\mathrm{P}^{*}$, $\mathrm{P} 1 *$ and $\mathrm{P} 2 *$, respectively.
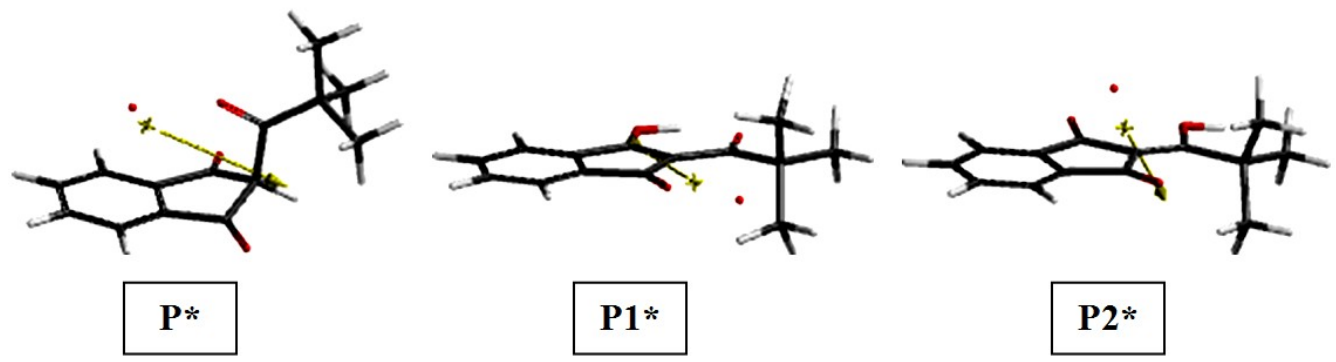

Figure 1. Optimized structures of the composite species considered.

Note that direction of the dipole moment of $\mathrm{P} 1 *\left(\mathrm{P} 1+\mathrm{Ca}^{++}\right)$is different from the others. Figures 2 and 3 show the electrostatic potential (ESP) and the natural charges, respectively on the atoms of the systems considered. It is worth mentioning that the ESP charges are obtained by the program based on a numerical method that generates charges that reproduce the electrostatic potential field from the entire wavefunction [31]. 

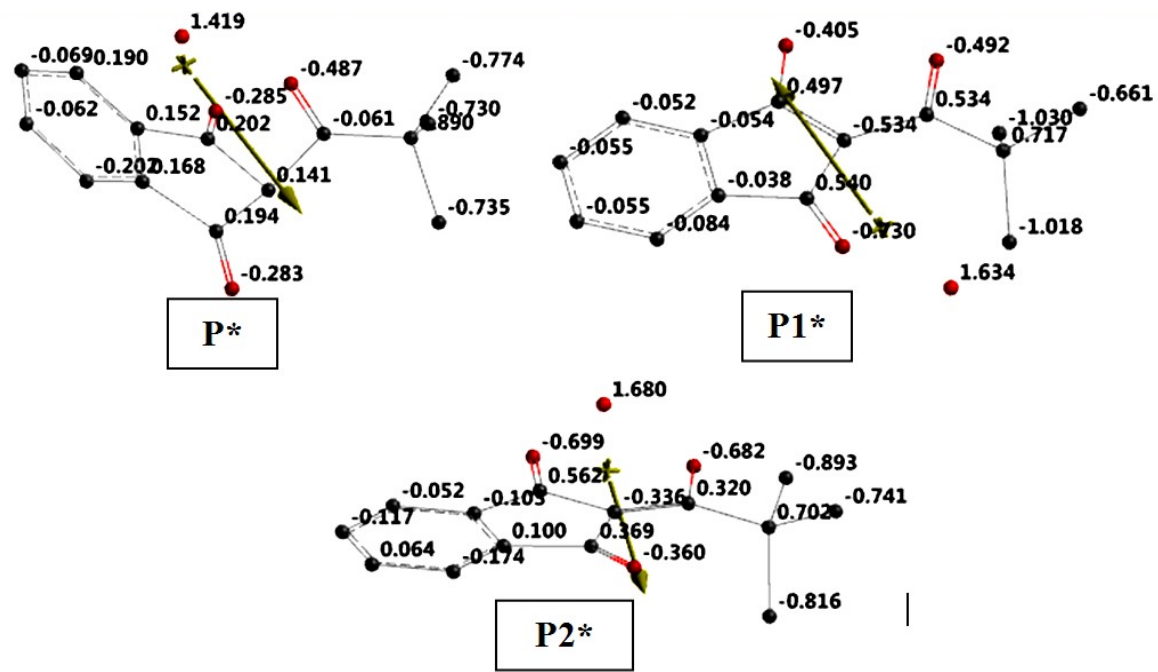

Figure 2. ESP charges on the atoms of the composite structures considered (Hydrogens not shown).

From Figures 2 and 3 it is evident that as a result of interaction with the species considered, the charge on the calcium atom decreases. The positive charge on the calcium atom then has the order of $\mathrm{P} 2 *>\mathrm{P} 1 *>\mathrm{P} *$ according to the ESP charge calculations and $\mathrm{P} 2^{*}>\mathrm{P} 1^{*}=\mathrm{P}^{*}$ order is obtained by the natural charge calculations.
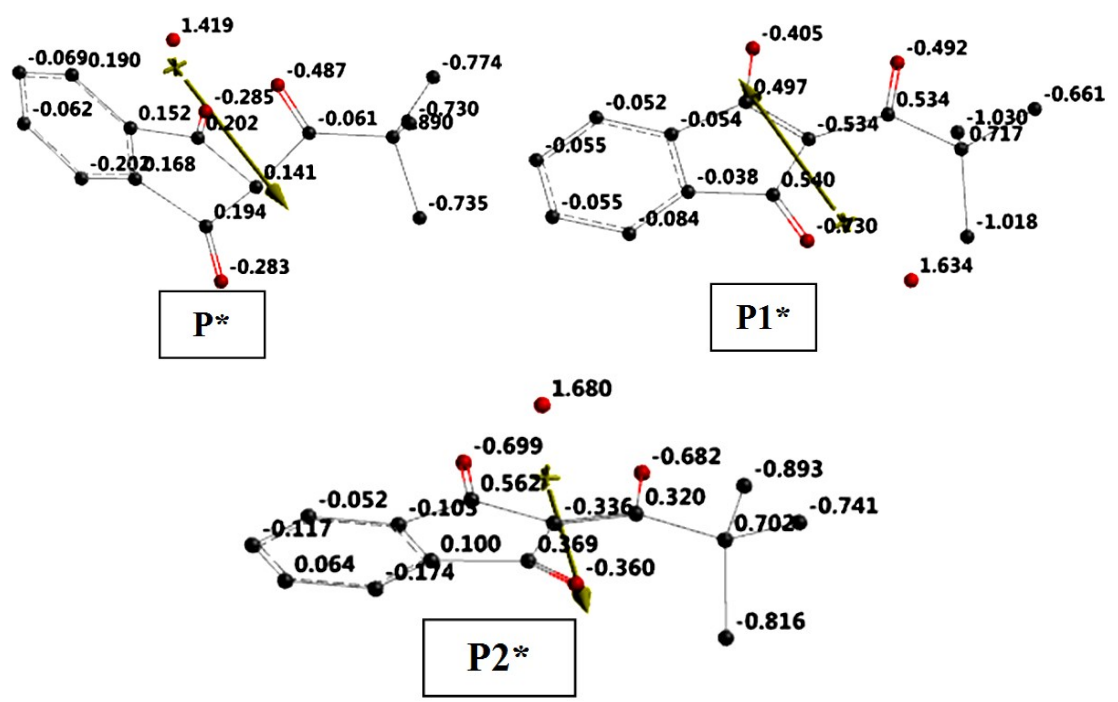

Figure 3. Natural charges on the atoms of the structures considered (Hydrogens not shown). 
The calculated dipole moments of these composite structures are 15.82, 20.54 and 24.44 debye for $\mathrm{P}^{*}, \mathrm{P} 1 *$ and $\mathrm{P} 2 *$, respectively. Whereas dipole moments of $\mathrm{P}, \mathrm{P} 1$ and $\mathrm{P} 2$ are $2.26,2.87$ and 2.20 debye, respectively.

Note that the positive charge on the calcium atom is greater than the others in the case of $\mathrm{P} 2 *$. Probably, the charge-dipole interactions are greater in $\mathrm{P} 2 *$, hence its formation is favored. On the other hand, the charge on the calcium atom in $\mathrm{P}^{*}$ and $\mathrm{P} 1 *$ cases are less than the charge in $\mathrm{P} 2 *$ which means some electron population has been transferred to the calcium ion in $\mathrm{P}^{*}$ and $\mathrm{P} 1 *$. On the other hand, ionic activity is proportional with charge of an ion and ionic strength (which is also a function of magnitude of charge of the ion) [32]. Thus, the activity of calcium ion in $\mathrm{P}^{*}$ and $\mathrm{P} 1 *$ cases should be less than the activity of it in P2*. Consequently, P or P1 by causing decrease of the activity of calcium should lead to more anticoagulative effect on the mechanism of coagulation.

Figures 4 and 5 display the IR spectra of pindone and its tautomers and the respective
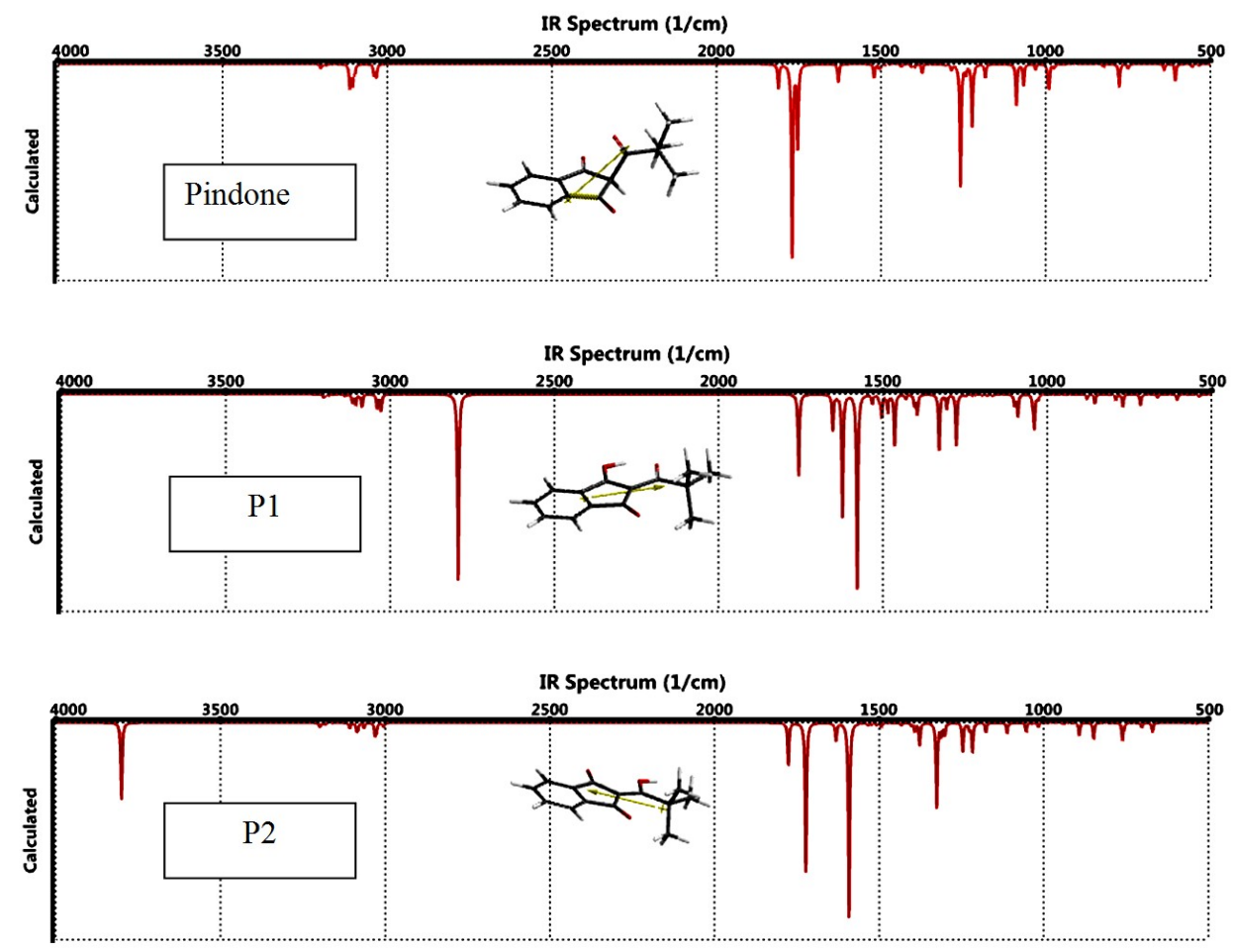

Figure 4. Calculated IR spectra of pindone and its tautomers considered. 
respective composite structures considered. Note that the both series are the products of the same level.

Pindone carbonyl stretchings occur at $1750-1770 \mathrm{~cm}^{-1}$. The skeletal breathing of the aromatic ring happens at $1258 \mathrm{~cm}^{-1}$. In $\mathrm{P} 1$ enolic $\mathrm{O}-\mathrm{H}$ stretching is at $2793 \mathrm{~cm}^{-1}$ and the carbonyl of cyclic part has $\mathrm{C}=\mathrm{O}$ stretching at $1756 \mathrm{~cm}^{-1}$. Whereas the carbonyl of the substituent occurs at $1623 \mathrm{~cm}^{-1}$. As for P2, the enolic $\mathrm{O}-\mathrm{H}$ stretching is at $3800 \mathrm{~cm}^{-1}$. The ring carbonyl stretches at $1723 \mathrm{~cm}^{-1}$. The peak at $1591 \mathrm{~cm}^{-1}$ stands for enolic $\mathrm{C}=\mathrm{C}$ stretching. The presence of calcium cation causes some changes in the IR spectra of pindone and is tautomers (compare Figures 4 and 5). In the composite of pindone ( $\left.\mathrm{P}^{*}\right)$ the ring carbonyl stretchings occur at $1831 \mathrm{~cm}^{-1}$ whereas the carbonyl of the substituent is observed at $1547 \mathrm{~cm}^{-1}$. In $\mathrm{P} 1 *$ the enol $\mathrm{O}-\mathrm{H}$ ketone $\mathrm{C}=\mathrm{O}$ stretchings occur at 3050 $\mathrm{cm}^{-1}$ and $1512 \mathrm{~cm}^{-1}$, respectively. Those stretchings in $\mathrm{P} 2 *$ happen at 3514 and 1815 $\mathrm{cm}^{-1}$, respectively and coupled with various other vibrations.
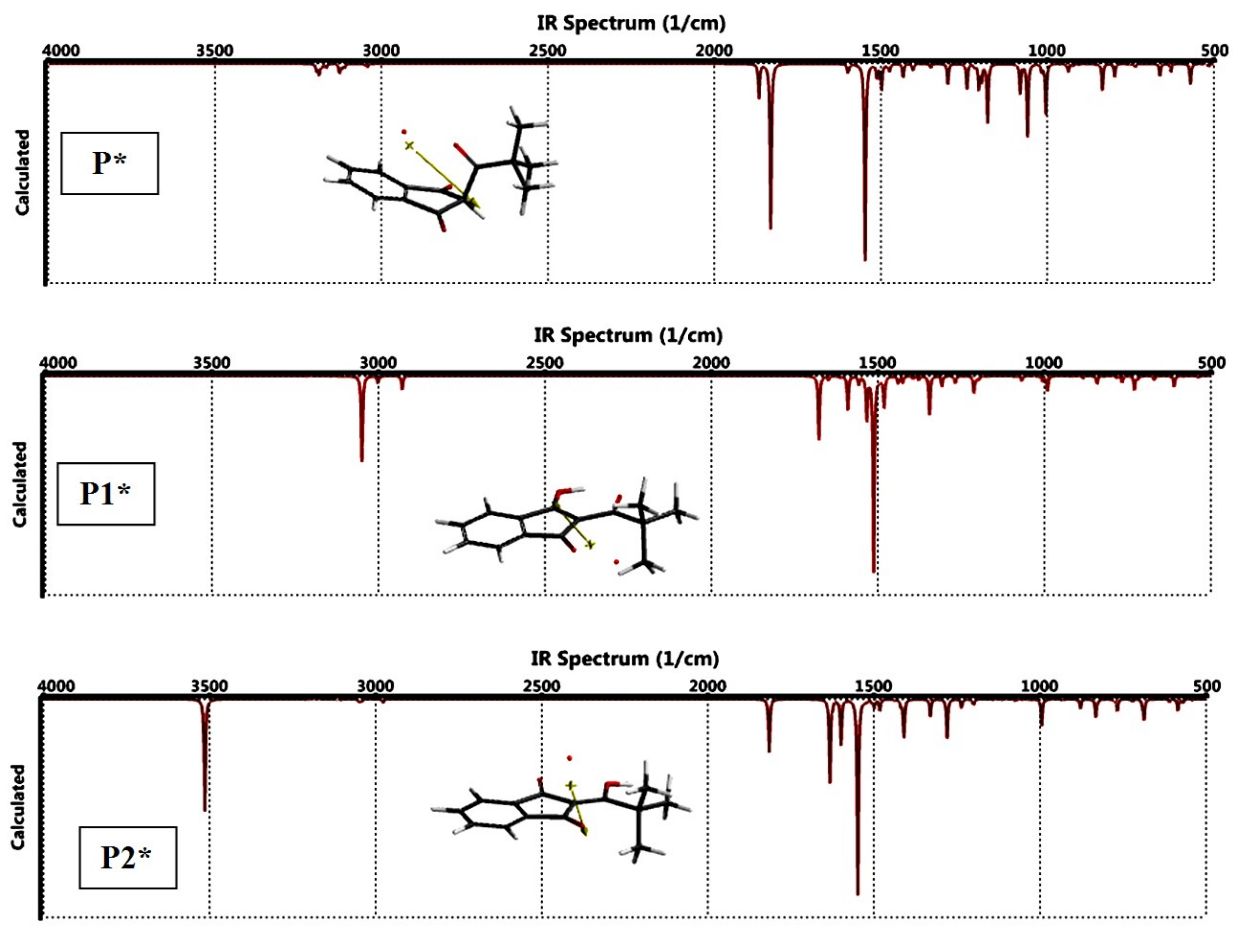

Figure 5. Calculated IR spectra of the composite species considered. 
Table 1 shows some energies of the composite species presently considered. In the table $\mathrm{E}, \mathrm{ZPE}$ and $\mathrm{E}_{\mathrm{c}}$ are the total electronic energy, zero point vibrational energy and the corrected total electronic energy, respectively. The $E_{c}$ values indicate that the electronically favored stability order is $\mathrm{P} 2 *>\mathrm{P} 1 *>\mathrm{P} *$.

Table 1. Some energies of the structures.

\begin{tabular}{cccc}
\hline & $\mathbf{E}$ & $\mathbf{Z P E}$ & $\mathbf{E}_{\mathbf{c}}$ \\
\hline $\mathbf{P *}$ & -3793580.44 & 651.825142 & -3792928.615 \\
$\mathbf{P 1} *$ & -3793636.00 & 655.141921 & -3792980.858 \\
$\mathbf{P 2} *$ & -3793648.28 & 655.455584 & -3792992.824 \\
\hline
\end{tabular}

Energies in $\mathrm{kJ} / \mathrm{mol}$.

Table 2 displays the calculated Gibbs free energies of pindone and its tautomers and their composites with $\mathrm{Ca}^{++}$. The $\mathrm{G}^{\circ}$ values of pindone series follow the order of $\mathrm{P} 1<\mathrm{P}<\mathrm{P} 2$ whereas the composites possess the order of $\mathrm{P} 2 *<\mathrm{P} 1 *<\mathrm{P} *$.

In the table $\Delta \mathrm{G}^{\circ}=\Delta \mathrm{G}^{\circ}\left(\mathrm{Pi} \rightarrow \mathrm{Pi}^{*}\right)-\mathrm{G}^{\circ}\left(\mathrm{Ca}^{++}\right)$. Then, $\Delta \mathrm{G}^{\circ}$ values in the table indicate that $\mathrm{Ca}^{++}$interacts with pindone and its tautomers in the order of $\mathrm{P} 2>\mathrm{P} 1>\mathrm{P}$. In other words $\mathrm{P} 2 *$ formation is more favorable than the others.

Table 2. Gibbs free energy values of the species of concern.

\begin{tabular}{ccccc}
\hline Specie & $\mathbf{G}^{\circ}$ & Specie & $\mathbf{G}^{\circ}$ & $\Delta \mathbf{G}^{\circ}$ \\
\hline $\mathbf{P}$ & -2015359.681 & $\mathbf{P}^{*}$ & -3793071.065 & -1777711.384 \\
$\mathbf{P 1}$ & -2015377.908 & $\mathbf{P 1} *$ & -3793121.869 & -1777743.961 \\
$\mathbf{P 2}$ & -2015327.758 & $\mathbf{P 2} *$ & -3793134.865 & -1777807.107 \\
\hline
\end{tabular}

Energies in $\mathrm{kJ} / \mathrm{mol}$. $\mathrm{P}_{\mathrm{i}}{ }^{*}$ stands for $\mathrm{Ca}^{++}$composite of $\mathrm{P}_{\mathrm{i}}$.

Figures 6 and 7 stand for the calculated UV-VIS spectra of pindone (and its tautomers) and their composites, respectively (all at the same level of calculations). The effect of calcium dication is clearly seen by the comparison of the spectra. 

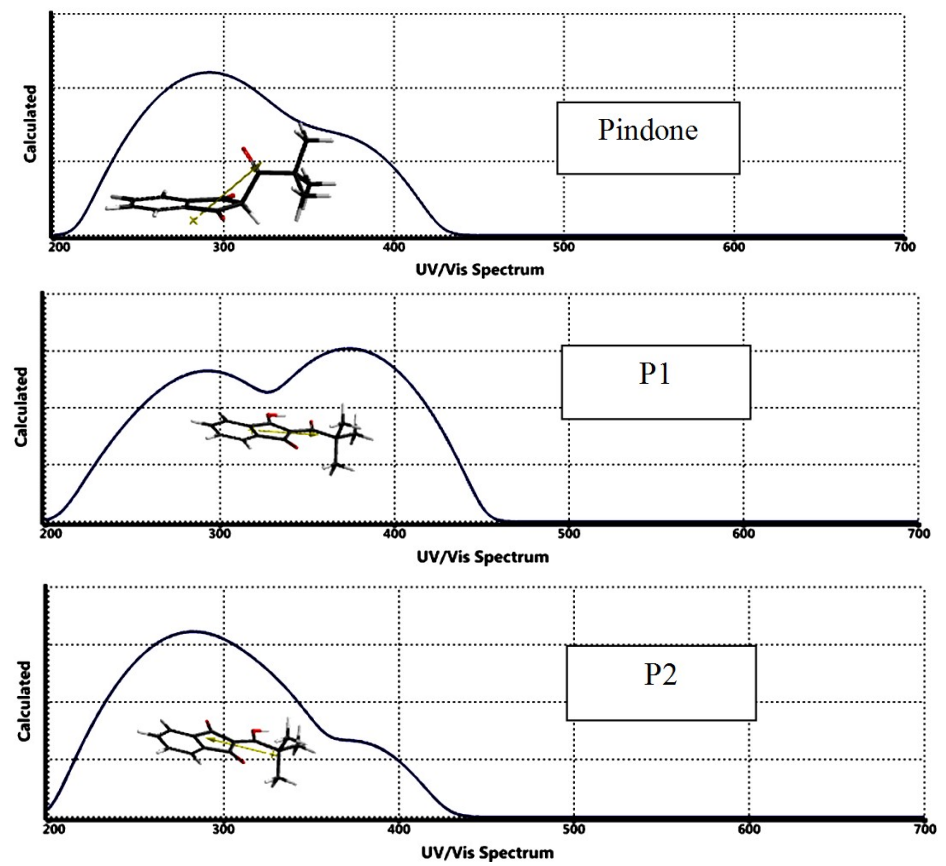

Figure 6. Calculated UV-VIS spectra of pindone and its tautomers considered.
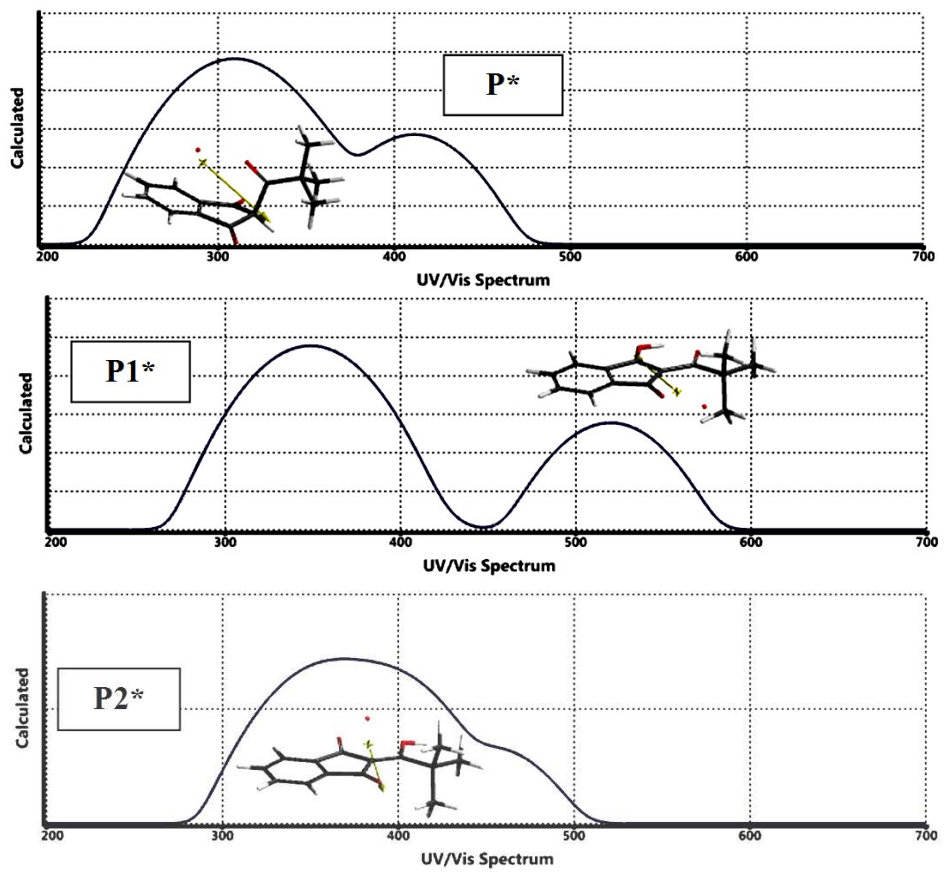

Figure 7. UV-VIS spectra of the composite species considered. 
Compared to the spectrum of $\mathrm{P}^{*}$ (Figure 7), the spectra of $\mathrm{P} 1 *$ and $\mathrm{P} 2 *$ exhibit some bathochromic effect, namely shift to longer wavelengths. However, this shift occurs in $\mathrm{P} 1 *$ so that affecting both of the $\lambda_{\max 1}$ and $\lambda_{\max 2}$. Whereas, in $\mathrm{P} 2 *$ only $\lambda_{\max 1}$ undergoes to longer wavelengths. Note that in $\mathrm{P} 1 *$ there exists more extended conjugation than the other species which could be the reason for the different appearance of its spectrum from the others.

Figure 8 shows some of the molecular orbital energy levels of the composite structures.
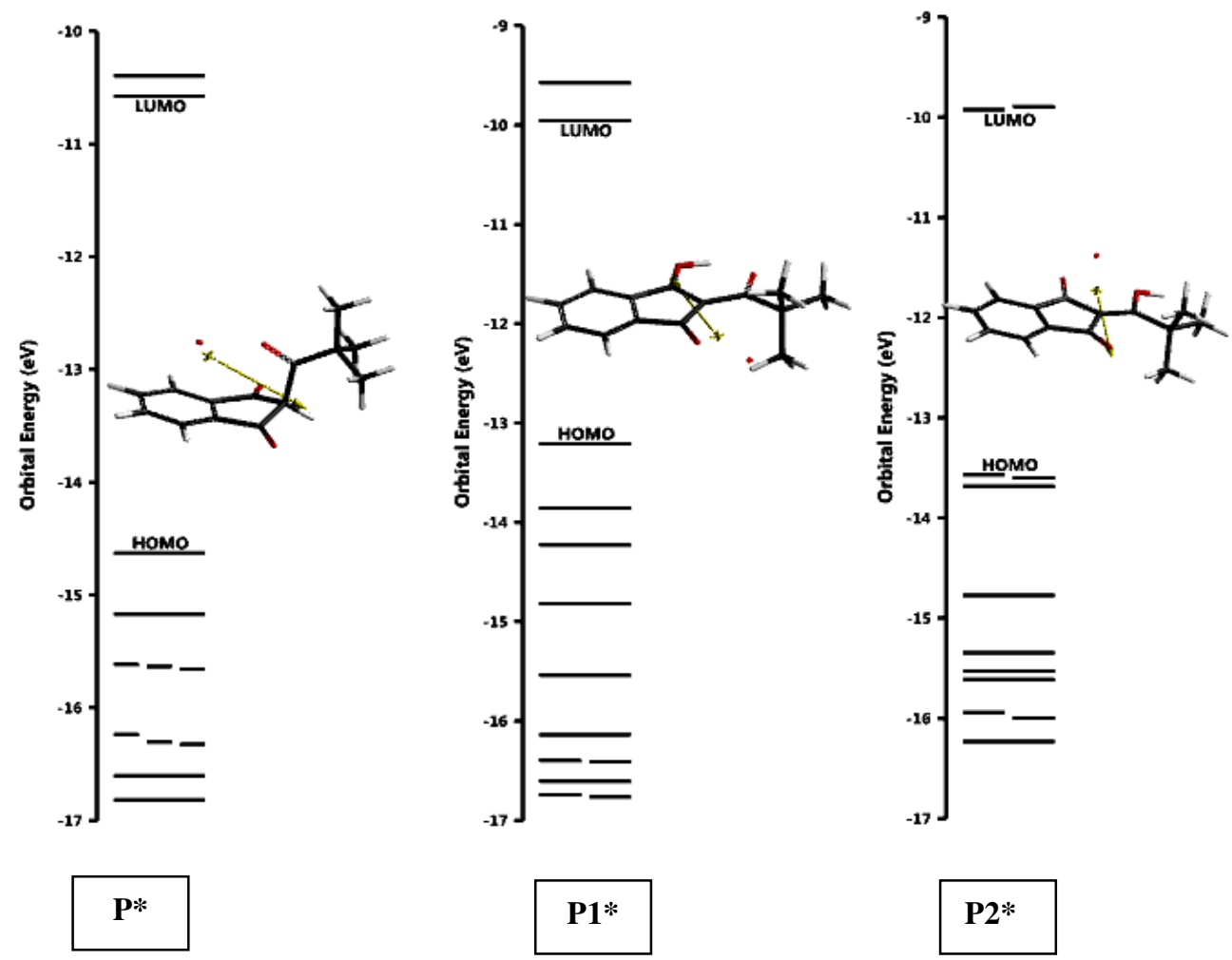

Figure 8. Some of the molecular orbital energy levels of the structures.

As seen in the figure, $\mathrm{P}^{*}$ is the lowest $\mathrm{HOMO}$ and $\mathrm{P} 1^{*}$ is the highest $\mathrm{HOMO}$ possessors among the composites.

Table 3 shows the HOMO, LUMO energies and the interfrontier molecular orbital energy gaps of the composites. 
Table 3. The HOMO, LUMO energies and the interfrontier molecular orbital energy gaps of the composites.

\begin{tabular}{cccc}
\hline Specie & HOMO & LUMO & $\Delta \boldsymbol{\varepsilon}$ \\
\hline P* & -1411.27031 & -1020.40685 & 390.8635 \\
P1* & -1274.36937 & -960.598755 & 313.7706 \\
P2* & -1309.17140 & -957.532149 & 351.6393 \\
\hline
\end{tabular}

Energies in $\mathrm{kJ} / \mathrm{mol}$.

The HOMO and LUMO levels of the composites follow the order of $\mathrm{P} *<\mathrm{P} 2 *<\mathrm{P} 1 *$ and $\mathrm{P}^{*}<\mathrm{P} 1 *<\mathrm{P} 2^{*}$, respectively. Consequently, the interfrontier molecular orbital energy gaps $(\Delta \varepsilon)$ follows the order of $\mathrm{P} *>\mathrm{P} 2 *>\mathrm{P} 1 *$ (see Figures 7 and 8 ).
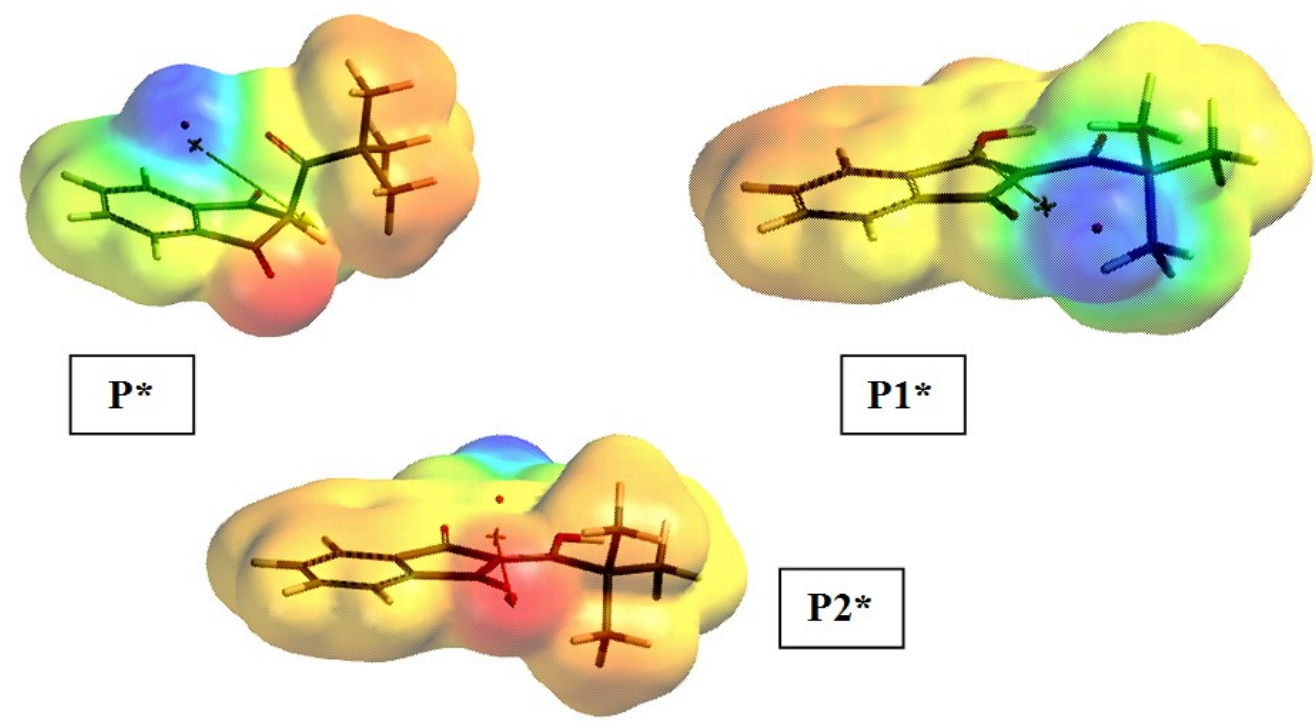

\section{P2*}

Figure 9. Electrostatic potential maps of the structures.

Figure 9 shows the electrostatic potential maps of the structures where the regions having shades of blue and red stand for positive and negative potential regions, respectively. The positive regions are around the calcium cation whereas negative regions are especially coincide with carbonyl oxygen(s) in pindone moiety of $\mathrm{P}^{*}$ and $\mathrm{P} 2$ *. 


\section{Conclusion}

The present investigation within the constraints of density functional theory at the level of calculations performed, has revealed that $\mathrm{Ca}^{++}$strongly interacts with pindone and its tautomers at the molecular level. The interaction should highly influence the anticoagulant effect of these species on the coagulation mechanism (beside any pindoneinduced some other anticoagulative mechanisms) so that exocyclic enol, P2, should be less effective anticoagulant than pindone and endocyclic enol P1.

\section{References}

[1] R. Cremlyn, Pesticides; Preparation and Mode of Action, NY: Wiley, 1978.

[2] J. R. Beauregard, T. W. Tusing and R. F. Hanzal, Anticoagulant rodenticide, toxicity and antidotal studies on 2-pivalyl-1,3-indandione (pival), an anticoagulant rodenticide, $J$. Agric. Food Chem. 32 (1955), 124-127. https://doi.org/10.1021/jf60048a002

[3] C. T. Eason and S. E. Jolly, Anticoagulant effects of pindone in the rabbit and Australian Bushtail Possum, Wildlife Research 20(3) (1993), 371-374. https://doi.org/10.1071/WR9930371

[4] G. R. Martin, R. J. Sutherland, I. D. Robertson, D. R. King and P. J. Hood, Assessment of the potential toxicity of a poison for rabbits, pindone (2-pivalyl 1, 3 indandione), to domestic animals, Australian Veterinary Journal 68(7) (1991), 241-243. https://doi.org/10.1111/j.1751-0813.1991.tb03217.x

[5] M. H. Robinson, L. E. Twigg, S. H. Wheeler and G. R. Martin, Effect of the anticoagulant, pindone, on the breeding performance and survival of merino sheep, Ovis aries, Comparative Biochemistry and Physiology Part B: Biochemistry and Molecular Biology 140(3) (2005), 465-73. https://doi.org/10.1016/j.cbpc.2004.11.011

[6] B. Sendra, S. Panadero and A. G. Hens, Determination of pindone in baits by using timeresolved lanthanide-sensitized luminescence and kinetic methodology, Analytical Letters 32(9) (1999), 1835-1846. https://doi.org/10.1080/00032719908542937

[7] I. Csöregh and R. Norrestam, The crystal and molecular structure of 2-pivaloyl-1,3indandione, Acta Cryst. B32 (1976), 2450-2455.

https://doi.org/10.1107/S0567740876007954

[8] J. D. Pipkin and V. J. Stella, Tautomerism of phenindione, 2-phenyl-1,3-indandione, in dipolar aprotic/hydrocarbon solvent mixtures, J. Am. Chem. Soc. 104(24) (1982), 66726680. https://doi.org/10.1021/ja00388a033 
[9] N. Hocaoğlu, T. Uyar and L. Türker, The syntheses of some novel 2-substituted phenylazo-1,3-indandiones, Dyes and Pigments 12(3) (1990), 187-195.

https://doi.org/10.1016/0143-7208(90)85011-C

[10] V. Enchev, MNDO and AM1 quantum-chemical study of tautomerism of 2-substituted 1,3-Indandiones, Chem. Papers 48(4) (1994), 219-222.

[11] M. V. Sigalov, Keto-enol tautomerism of phenindione and its derivatives: an NMR and density functional theory (DFT) reinvestigation, J. Phys. Chem. A 1198 (2015), 14041414. https://doi.org/10.1021/jp512461c

[12] P. J. Savarie, The Nature, Modes of Action, and Toxicity of Rodenticides, CRC Handbook of Pest Management, Boca Raton, Florida: CRC Press, 1981.

[13] G. R. Martin, R. J. Sutherland, I. D. Robertson, W. E. Kirkpatrick, D. R. King and P. J. Hood, Assessment of the potential toxicity of a poison for rabbits, pindone (2-pivalyl 1,3indandione), to domestic animals, Australian Veterinary Journal 68 (1991), 241-243. https://doi.org/10.1111/j.1751-0813.1991.tb03217.x

[14] E. W. Bentley, A review of anticoagulant rodenticides in current use, Bulletin of World Health Organisation 47 (1972), 275-280.

[15] M. E. Mount and B. F. Feldman, Mechanism of diphacinone rodenticide toxicosis in the dog and its therapeutic implications, American Journal of Veterinary Research 44(11) (1983), 2009-2017.

[16] A. White, P. Handler and E. L. Smith, Principles of Biochemistry, NY: McGraw-Hill, 1968.

[17] R. K. Murray, D. K. Granner, P. R. Mayers and V. W. Rodwell, Harper's Biochemistry, California: Appleton and Lange, 1993.

[18] J. F. Mustard, E. A. Murphy, H. C. Rowsell and H. G. Downie, Factors influencing thrombus formation in vivo, The American Journal of Medicine 33(5) (1962), 621-647. https://doi.org/10.1016/0002-9343(62)90243-7

[19] S. Palta, R. Saroa and A. Palta, Overview of the coagulation system, Indian J. Anaesth. 58(5) (2014), 515-523. https://doi.org/10.4103/0019-5049.144643

[20] L. Muszbek, Z. Bagoly, Z. Bereczky and E. Katona, The involvement of blood coagulation factor XIII in fibrinolysis and thrombosis, Cardiovascular and Hematological Agents in Medicinal Chemistry 6 (2008), 190-205.

https://doi.org/10.2174/187152508784871990 
[21] J. J. P. Stewart, Optimization of parameters for semiempirical methods I. Method, J. Comput. Chem. 10 (1989), 209-220. https://doi.org/10.1002/jcc.540100208

[22] J. J. P. Stewart, Optimization of parameters for semi empirical methods II. Application, J. Comput. Chem. 10 (1989), 221-264. https://doi.org/10.1002/jcc.540100209

[23] A. R. Leach, Molecular Modeling, Essex: Longman, 1997.

[24] P. Fletcher, Practical Methods of Optimization, New York: Wiley, 1990.

[25] W. Kohn and L. J. Sham, Self-consistent equations including exchange and correlation effects, Phys. Rev. 140 (1965), 1133-1138. https://doi.org/10.1103/PhysRev.140.A1133

[26] R. G. Parr and W. Yang, Density Functional Theory of Atoms and Molecules, London: Oxford University Press, 1989.

[27] A. D. Becke, Density-functional exchange-energy approximation with correct asymptotic behavior, Phys. Rev. A 38 (1988), 3098-3100. https://doi.org/10.1103/PhysRevA.38.3098

[28] S. H. Vosko, L. Wilk and M. Nusair, Accurate spin-dependent electron liquid correlation energies for local spin density calculations: a critical analysis, Can. J. Phys. 58 (1980), 1200-1211. https://doi.org/10.1139/p80-159

[29] C. Lee, W. Yang and R. G. Parr, Development of the Colle-Salvetti correlation-energy formula into a functional of the electron density, Phys. Rev. B 37 (1988), 785-789. https://doi.org/10.1103/PhysRevB.37.785

[30] SPARTAN 06, Wavefunction Inc., Irvine CA, USA, 2006.

[31] L. Türker, Tautomerism in pindone - a DFT study, Earthline J. Chem. Sci. 3(1) (2020), 35-50. https://doi.org/10.34198/ejcs.3120.3550

[32] P. Atkins and J. de Paula, Atkins’ Physical Chemistry, Oxford: Oxford Press, 2002. 